\title{
Evolution of the pterosaur pelvis
}

Elaine S. Hyder, Mark P. Witton, and David M. Martill

Acta Palaeontologica Polonica 59 (1), 2014: 109-124 doi: http://dx.doi.org/10.4202/app.2011.1109

Pterosaur pelvic girdles are complex structures that offer a wealth of phylogenetic and biomechanical information, but have been largely overlooked by pterosaur anatomists. Here, we review pterosaur pelvic morphology and find significant differences that correlate well with pterosaur clades identified in some phylogenetic analyses. We find that the length and orientation of the iliac processes, position of the acetabulum, extent of the ischiopubic plate and presence of supraneural fusion in adult individuals are taxonomically informative. Ontogenetic changes in pelvic morphology dictate that osteologically mature specimens are required to assess the development of many of these characteristics. We suggest that pelvic characters can readily be incorporated into pterosaur phylogenetic analyses and may assist in resolving the controversial interrelationships of this group. Distinctive pterosaur pelvic morphotypes suggest considerable differences in stance, locomotory kinematics and hindlimb functionality across the group.

Key words: Pterosauria, pelvis, phylogeny, terrestrial locomotion.

Elaine S. Hyder [elainesh1@aol.com], Mark P. Witton [mark.witton@port.ac.uk ], David M. Martill [david.martill@ port.ac.uk], School of Earth and Environmental Sciences, University of Portsmouth, Burnaby Building, Burnaby Road, Portsmouth, PO1 3QL, UK.

This is an open-access article distributed under the terms of the Creative Commons Attribution License (for details please see creativecommons.org), which permits unrestricted use, distribution, and reproduction in any medium, provided the original author and source are credited. 